\title{
Effects of Compacted Forms (Stick and Pellet Fuels) of Rice Husks as Fuel Use on Silica Solubility for Fertilizer Use
}

\section{Ryoko Sekifuji}

Toyama Kenritsu Daigaku

\section{Le Van Chieu}

Vietnam National University University of Science

Masafumi Tateda ( $\square$ tateda@pu-toyama.ac.jp)

Toyama Kenritsu Daigaku - Toyama Campus https://orcid.org/0000-0001-7558-4416

\section{Hiroshi Takimoto}

Ishikawa Prefectural University: Ishikawa Kenritsu Daigaku

\section{Research}

Keywords: rice husks, fuel, pelletization, solidification, solubility, fertilizer, silica

Posted Date: June 9th, 2021

DOI: https://doi.org/10.21203/rs.3.rs-544390/v1

License: (c) (i) This work is licensed under a Creative Commons Attribution 4.0 International License. Read Full License 


\section{Abstract}

Extremely lightweight of rice husks due to low specific gravity is disadvantageous for accelerating its usage. To overcome this disadvantage, rice husks are sometimes compacted, that is, pelletized or solidified to assist easy and cheap collection and hauling. However, the compaction process may negatively affect the properties of silica in the husk. In this study, the influence of the compaction process was studied through the solubility and physical properties of silica. Two types of fuels, pellet and stick fuels, were synthesized and their influence on the properties of the fuel ash was evaluated. Consequently, stick fuels were better than pellet fuels in terms of fertilizer use of the ash during their use in residential stoves and small commercial heaters. Contrastingly, rice husks in the existing form were better than stick fuels under washing conditions; however, rice husks had disadvantages in terms of cost and handling during collection and hauling. Selection of rice husks in their existing form or compacted rice husks must be carefully considered based on the business approaches of the stakeholders.

\section{Introduction}

The development and the subsequent applications of recycling technology are important for waste recycling; however, collection and hauling are important aspects since their costs may impose financial burdens on the recycling scheme [1]. Rice husks are problematic for rice stakeholders due to their bulky nature, which has disadvantages during hauling for long distances since their specific gravity is 0.1 ton/m3 [1]. Therefore, rice husks should be compacted as pellets or sticks 10 times more than the existing forms of rice husks, when they are to be hauled for long distances. Additionally, compact forms, such as pellets and solids may be good for the use of rice husks as fuels due to their low collection and hauling costs. Since rice husks possess approximately heating value of $12 \mathrm{MJ} / \mathrm{kg}$ (dry base) of energy, they serve as potential fuel sources and have also been used in the past. Sheng and Azevedo (2005) proposed that the estimation of the biomass heating value should be conducted for various biomass component properties and chemical compositions [2]. Multiple studies have assessed the use of rice husks as fuels, such as biochar [3], for hot water production [4], for synthesis of mixed fuel for electric generation [5], solid fuel through torrefaction [6], fuel by fluidized-bed combustion [7], power generation by gasification [8], three conversion technologies (hydrothermal carbonization with pelletization, pyrolysis, and anaerobic co-digestion processes) for rice husk-to-fuel [9], and thermal bioconversion, including ethanol production technologies [10]. Quispe et al. (2017) studied various agricultural residues and transformed rice husks into fuel through pyrolysis [11]. To use rice husks as a fuel source, complete recycling of rice husk incineration ash is required [1]. The biggest challenge of using rice husks as a fuel source is that they leave behind a large amount of silica ash residue, which is approximately $20 \%$ in weight, after incineration. The different rice stakeholders, thus, face a difficulty in managing the ash in the absence of proper ash management. Therefore, the application of silica fertilizers in paddy fields has been proposed for the complete use of ash [12]. Rice plants are known to require intensive silica for their healthy growth. Since rice is the staple food of Japanese citizens, the demand of silica is high to facilitate large-scale production of rice. Presently, silica is being imported to Japanese paddy fields. 
However, silica originating from rice husks of the Japanese rice fields (called as indigenous silica) can serve as a good substitute to imported silica. This basic concept has been illustrated in Fig. 1.

In Japan, after paddy harvest in autumn, the paddy devoid of straw is milled, resulting in the production of rice along with rice husk. The rice husks are burned in a boiler followed by heat recovery and $\mathrm{CO} 2$ recycling. Hot water or electricity is produced from the heat recovery process, and high value-added agricultural products are harvested from $\mathrm{CO} 2$ recycling [13]. For example, strawberries are known to become sweeter when grown in high $\mathrm{CO} 2$ environments. Incineration of the husks produces ash rich in silica content, which is subsequently used as a silica fertilizer. The use of exogenous silica fertilizers originating from other industrial sectors, such as iron industry in Japan could be substituted with ash containing indigenous silica originating from rice husks from Japanese paddy fields. Multiple applications of silica, such as in concrete, insulators, food, cosmetics, catalysts, detergents, solar panels, etc., have been reported [14]. However, we believe that the use of rice husk ash as a silica fertilizer is the best alternative for complete recycling of rice husk ash after heat recovery, especially in Japan, where the silica content in soil is very low [12]. The quality of the ash as a silica fertilizer for paddy fields has been evaluated by the solubility index of silica in rice husks [15]. The solubility of silica in the incineration ash of rice husks has been evaluated; however, the solubility of silica in incineration ash of rice husks in the form of compact pellets and sticks have not yet been studied. Therefore, the objective of this study was to evaluate the solubility and physical properties of silica in incineration ash of compact, pelletized, and solidified rice husks. Ríos-Badrán et al. (2020) synthesized pellet fuel and compared a fuel made of only rice husks to a mixture of rice husks and wheat [16]. Additionally, knowledge of how the compaction process affects the solubility of silica in rice husks is important when considering the use of rice husks as fuels. Many studies have found that silica has an extremely low solubility in water and a low availability of biogenic silica in water [17-20]. Silica forms with long availability periods are expected to have slow effects on rice plants, unlike silica gels and calcium silicate, and can be applied every year. The use of short materials as silica fertilizer in rice production, converting waste into resources, and heat recovery are significant achievements for rice production stakeholders globally.

\section{Materials And Methods}

\subsection{Sample preparation of rice husks and rice husk fuel}

Rice husks from Koshihikari (Oryza sativa L.) were used in this study. The risk husks were pelletized and solidified after washing the rice husks with $5 \%$ citric acid. Rice husks were placed in a laundry net and soaked in $5 \%$ citric acid solution at a 1:10 (rice husks: citric acid solution) ratio for $24 \mathrm{~h}$, rinsed with water, and dried for compaction. Pellet and stick fuels were produced by pelletization and solidification, respectively (Fig. 2). Pelletization and solidification were performed using KNP-701 and FHM-120, respectively (Fig. 3). The machine specifications are listed in Table 1. The stick fuel was about $30 \mathrm{~cm}$ long. Specific density of pellet and stick fuels were 1.4 and 1.2 ton/m3 (wet base, unpublished data), respectively, while that of the existing form of rice husks (as-are) was $0.11 \mathrm{ton} / \mathrm{m} 3$. Rice husks were washed with $5 \%$ acetic acid to determine the solubility of silica in the incineration ash. Acetic acid was 
selected for washing the as-are samples since it is cheaper (0.8 times) than citric acid; additionally, according to the previous studies, citric acid and acetic acid demonstrated similar washing efficiencies.

Table 1

Specs of Pelletization and Solidification Machines

\begin{tabular}{|lll|}
\hline Types (Maker Name) & KNP-701(Taiwa Seiki) & FHM-120 (Kansai Sangyo) \\
\hline Mechanism & $\begin{array}{l}\text { Crushing and extrusion- } \\
\text { compression molding }\end{array}$ & $\begin{array}{l}\text { Crushing and heated extrusion- } \\
\text { compression molding }\end{array}$ \\
$\begin{array}{l}\text { Size }(\text { Width } \times \text { Length } \\
\times \text { Height })\end{array}$ & $630 \times 1,090 \times 1,234 \mathrm{~mm}$ & $1,050 \times 2,465 \times 2,050 \mathrm{~mm}$ \\
\hline \begin{tabular}{l} 
Power Consumption \\
\hline
\end{tabular} & Three-phase 200V, $5.5 \mathrm{~kW}$ & Three-phase 200V, 19.9 kW \\
\hline
\end{tabular}

\subsection{Solubility measurement}

The solubility of silica in rice husk ash was measured by modifying the method described by Tateda et al. (2016) [15]. This method was based on the standard method 4.4.1.c [21], but the first step of hydrochloric acid treatment was skipped to save time. However, the results were similar to those projected by the standard method. No standardized method for measuring the solubility of rice-husk-derived silica currently exists; method 4.4.1.c was not designed for silica fertilizer made from rice husks, but for fertilizers containing silica gel.

\subsection{Measurement of the physical properties of rice-husk ash}

The physical properties of the rice-husk ash are good indicators for determining the quality of the ash [22]. The properties were estimated according to the relative contents of fixed carbon, ash, volatile solids, and moisture, which were determined by following JIS M 8812; the subsequent values for moisture content, ash, volatile solids, and fixed carbon were JIS M 8812 - 5.2.4a, 8812 - 6.4.1, 8812 - 7.2.4, and 8812-8, respectively [23]. Xray diffraction (XRD) was performed using MultiFlex (40 kV, 30 mA, CuKa, 20:5-80, Rigaku).

\subsection{Experimental procedure}

Approximately $60 \mathrm{~g}$ of the as-are washed (Fig. 4 (A)); pellet fuel (Fig. 4 (B)) and stick fuel (2.5 cm in length, Fig. 4 (C)) samples were placed in a stainless vat and calcinated in a laboratory-scale electric furnace (KBF794N1, Koyo) at $400-900^{\circ} \mathrm{C}$ for $15-60 \mathrm{~min}$. The ash of the pellet and stick fuels was powdered in a mixer, and the solubility of silica and the physical composition of rice-husk ash were measured. The solubility of the ash of as-are samples was measured without powdering. Experiments 
were performed in triplicates, and the corresponding mean values $(p<0.05)$ were used for statistical analysis.

\section{Results And Discussion}

\subsection{Incineration of pellet and stick fuels}

Figure 5 shows the status of ash of the two fuels after incinerating at $400-900^{\circ} \mathrm{C}$ for $15-60 \mathrm{~min}$.

As seen in Fig. 5, long durations of incineration and high temperatures led to whiter appearance of ash. Barring $900^{\circ} \mathrm{C}$, the ash appeared whiter at other temperatures with the increase in the duration of incineration. For pellet fuels, a mixture of white and black ash was observed. The white ash was located on the outer side, whereas the black ash was located on the inner side of the pellet when the pellet fuel was burned. Additionally, the ash on the outer and inner sides appeared merged in the photographs. The photographs of the stick fuels clearly indicated that the outer side was white, while the inner side was black, however; they appeared black at $900^{\circ} \mathrm{C}$. Figure 6 shows the powdered state of each fuel. Some stick fuels appeared extremely white at high temperatures and long durations of incineration (Fig. 5), but one powdered stick fuel was comparatively less white and appeared blacker than the powdered pellet fuels (Fig. 6), implying that only the surface of the stick fuels was white, while the ash underneath was black. After $15 \mathrm{~min}$, all the samples turned black, and the ash appeared white with increasing temperature. The color difference was evidently observed in the pellet samples in comparison to the stick samples.

\subsection{Effects of incineration temperatures and durations on the silica solubility}

The trends in solubility at different incineration temperatures are shown in Fig. 7. The solubility of pellet fuels (Fig. 7 (A)) varied at 15, 30, and $60 \mathrm{~min}$. Furthermore, the solubility at $60 \mathrm{~min}$ of incineration showed a radical fluctuation among the incineration temperatures; subsequently, the solubility was the highest among the three durations of incineration, decreased to $70 \%$ at $800^{\circ} \mathrm{C}$, and finally, to approximately $20 \%$ at $900^{\circ} \mathrm{C}$. The sample incinerated for $30 \mathrm{~min}$ consistently exhibited higher solubility than the $15 \mathrm{~min}$ sample with almost a similar solubility trend at $900^{\circ} \mathrm{C}$. The $15 \mathrm{~min}$ sample was very stable in terms of solubility at all temperatures, and remained nearly $50 \%$. Contrastingly, in the case of stick fuels, a narrow range of solubility was observed throughout the samples (Fig. 7 (B)). Radical fluctuations were not observed in any of the samples. The solubility of the sample after 60 min remained the highest, but it was almost similar to the other two duration samples at $900^{\circ} \mathrm{C}$. The most stable sample in terms of solubility was the 30 min sample with its solubility fluctuating between $40 \%$ and $50 \%$. The solubility of the pellet and stick fuel samples varied distinctly after $60 \mathrm{~min}$. The solubility of the pellet fuel after $60 \mathrm{~min}$ of incineration exceeded $80 \%$, which was the highest value at $500^{\circ} \mathrm{C}$, while that of the stick fuel reached only $60 \%$, which was the highest value for the stick fuel. A decreasing trend in solubility was observed for 
stick fuel samples than for pellet fuel samples since pellet fuel had a larger surface area than stick fuels. Formation of fuel might have led to these results.

Pellet fuel can be easily exposed to air because of its small size; conversely, stick fuel was not easily exposed to air due to its comparatively larger size and since it was made by compacting a larger mass of rice husks. As shown in Fig. 6, the color of the powdered stick fuel was blacker than that of the powdered pellet fuel, implying that the stick fuel exhibited poor burning performance than pellet fuel, leading to increased fixed carbon in the ash that consequently decreased the solubility.

The comparison between the solubility of the pellet and stick fuels for the same incineration duration has been shown in Fig. 8. Additionally, the solubility of the as-are unwashed and washed are shown. During 15 min of incineration (Fig. 8 (A)), the

solubility of the stick fuel was the lowest at $400^{\circ} \mathrm{C}$ and fluctuated in the range of $40-45 \%$ after $500^{\circ} \mathrm{C}$. Contrastingly, the solubility of the pellet fuel remained stable throughout the incineration temperature range of $400-900^{\circ} \mathrm{C}$. However, at the $30 \mathrm{~min}$ incineration duration, opposite solubility trends were observed for the pellet and stick fuels (Fig. 8 (B)). The solubility of the pellet fuel showed a decreasing trend with increasing calcination temperatures, while that of the stick fuel demonstrated an increasing trend as the temperature increased. However, the solubility of the two fuels was identical at $900^{\circ} \mathrm{C}$. For the 60 min incineration duration, high solubility was observed at $500^{\circ} \mathrm{C}$ for both fuels (Fig. 8 (C)). The solubility of the stick fuel fluctuated approximately between $50 \%$ and $60 \%$, while pellet fuel showed very high solubility and a drastic decrease at $900^{\circ} \mathrm{C}$. The lowest solubility was observed at $900^{\circ} \mathrm{C}$ for both fuels; the solubility of pellet fuel, especially, was $24.0 \%$ and the silica in the ash was already crystalized, which could be deduced based on the cristobalite peaks in the X-ray diffraction analysis results (data not shown).

Solubility trends of the as-are unwashed and washed are also shown in Fig. 8. The as-are washed samples, regardless of calcination duration, showed an increase in solubility at low temperatures and almost stable solubility trends up to $900^{\circ} \mathrm{C}$, while as-are unwashed samples showed a decrease in the solubility as the calcination temperature increased. The silica solubility of unwashed samples at $900^{\circ} \mathrm{C}$ for 30 and 60 min was very low with approximately $10 \%$ and less than $10 \%$, respectively, and the silica at 30 and 60 min was crystallized, while the silica at $900^{\circ} \mathrm{C}$ for $15 \mathrm{~min}$ was not crystallized (data not shown). The high differences in solubility trends between as-are unwashed and washed samples as a function of calcination temperatures are attributed to the presence of alkali metals, such as potassium, which originates from the fertilizer used during rice production. Potassium accelerates the crystallization temperature of silica [24-26]. Among the three calcination durations, regardless of washed and unwashed conditions, 15 min samples showed the lowest, but most stable solubility. Moreover, the difference in the appearance of the ash between the as-are unwashed and washed samples was evidently distinct (Fig. 9). Therefore, as-are unwashed or raw rice husks are not suitable as fuels and moreover, pellet fuel is not suitable, especially when they are used in a stove, where the generated ash stays for longer durations inside the stove because temperature reaches nearly $1,000^{\circ} \mathrm{C}$ [27]. Additionally, 
the ash generated at the bottom of the stove is not removed within an hour. Compact stick fuel may be better than compact pellet fuel; however, the solubility performance of the stick fuel is uncertain if the duration of incineration exceeds one hour because the solubility of stick fuel decreases after $800^{\circ} \mathrm{C}$.

As mentioned earlier, the two fuels used in this study were washed with acid before the compaction process. The solubility trends of the two fuels and the as-are washed samples were observed. Pellet fuel showed a similar solubility at the 60 min calcination duration at $500-800^{\circ} \mathrm{C}$ to that of the as-are washed samples (Fig. 8), but the trends between the two fuels were not completely similar; conversely, the solubility trends between stick fuel and as-are washed samples were very similar, although the values of solubility were different.

\subsection{Results of the physical properties}

Figure 10 shows the physical properties of rice husk ash after calcination at different calcination temperatures and durations and the corresponding solubility at each condition. On comparing the physical properties in the ash of compact rice husks (pellet and stick fuels) and uncompact as-are unwashed and washed, we observed that fixed carbon majorly remained in the ash of compact rice husks. Additionally, a large proportion of fixed carbon remained in the $60 \mathrm{~min}$-calcination stick fuel sample of the ash, indicating that highly dense compact fuel might not receive enough heat, especially the interior of the fuel sample, to burn the fixed carbon.

The observations in Figs. 5 and 6 support this discussion because, as mentioned earlier, the superficially white appearance of the stick fuel samples at $600-800^{\circ} \mathrm{C}$ for $60 \mathrm{~min}$ turned black when the samples were powdered; conversely, the pellet fuel samples remained white for the same conditions. This implies that the stick fuels beneath the outside layer did not receive enough heat and retained high proportion of fixed carbon inside the fuel. Compact pellet fuel performed better in terms of heat penetration than stick fuel, and its fixed carbon content was significantly different from that of the stick fuel for 60 min of calcination. The difference in the surface area supports this discussion. The surface areas of $60 \mathrm{~g}$ each of pellet and stick fuels (Fig. 4) were approximately $342 \mathrm{~cm} 2$ and $100 \mathrm{~cm} 2$, respectively. Since the surface area of pellet fuel was three times more than that of stick fuels, pellet fuels burned more effectively than stick fuels.

Figure 10 shows also the solubility of the silica in ash. On comparing the content of the ash portion with the solubility value, the status of the silica in the ash can be estimated. The solubility indicates the proportion of soluble silica in the ash. It should be clear here that "the ash portion" and "the ash" are different. On calcination, rice husks become ash. The ash is composed of ash, water, volatile solids, and fixed carbon portions. Among these, the ash portion majorly consists of silica and less than $2 \%$ of oxides, such as $\mathrm{Al} 2 \mathrm{O} 3, \mathrm{CaO}, \mathrm{Na} 2 \mathrm{O}, \mathrm{K} 2 \mathrm{O}, \mathrm{P} 2 \mathrm{O} 5, \mathrm{Fe} 2 \mathrm{O3}$, etc.; therefore, the ash portion is approximately equal to silica (data not shown). The physical state of silica changes with changes in the temperature and incineration duration. Silica in rice husks is originally amorphous and turns to crystalline form at high temperatures and long durations of incinerations. The silica in the three samples, as-are unwashed at $900^{\circ} \mathrm{C}$ and $30 \mathrm{~min}$, as-are unwashed at $900^{\circ} \mathrm{C}$ and $60 \mathrm{~min}$, and pellet fuel at $900^{\circ} \mathrm{C}$ and $60 \mathrm{~min}$, was 
crystalized (Fig. 10). However, the silica in other samples was not crystalline (Fig. 10), but the silica in some instances was in the intermediate state or the insoluble state (Fig. 11). When the percentage of the ash portion and that of the silica solubility is same, for example, in case of majority of the samples at 400 and $500^{\circ} \mathrm{C}$ (Fig. 10), we can assume that the entire silica content in the ash was soluble. The 15 and $30 \mathrm{~min}$ as-are washed samples followed this trend at approximately all the calcination temperatures. When the percentage of the ash portion was higher than that of silica solubility, the excess ash percentage was considered as "insoluble silica." For example, in case of $30 \mathrm{~min}$ samples of pellet fuel, the ash portion percentage and the solubility percentage were the same at 400 and $500^{\circ} \mathrm{C}$, indicating that all silica in the ash was soluble. Later, the solubility percentages decreased, while the percentage of the ash portion remained constant. Finally, the two percentages started differing at $600^{\circ} \mathrm{C}$ and above $600^{\circ} \mathrm{C}$. The percentage of the ash portion was higher than that of soluble silica and the corresponding excess percentage of the ash portion was considered as "insoluble silica." At $900^{\circ} \mathrm{C}$, the ash portion was $68.6 \%$ and the solubility was approximately $45.2 \%$; the excess percentage of approximately $23.4 \%$ was "insoluble silica." In the case of $60 \mathrm{~min}$ pellet fuel sample at $900^{\circ} \mathrm{C}$, the ash portion was approximately $95.2 \%$ and the solubility was $24.2 \%$; the excess percentage of the ash portion was $71.0 \%$. In this case, silica was crystalized according to the XRD analysis; $71.0 \%$ of ash consisted of crystalline and insoluble silica even though those percentages were not distinct based on the analysis conducted in this study. Since crystalline and insoluble silica are not suitable for silica fertilizer, the ash with equal percentage as that of solubility is ideal.

The use of the two types of fuels discussed in this study mainly targeted residential stoves or small commercial heaters. The ash generated from burning rice husks in stoves and heaters is usually exposed to high temperatures and stays for long durations in the stoves and heaters. Therefore, stick fuel was better than pellet fuel because the solubility trends of stick fuel as a function of calcination temperatures were more stable than those of pellet fuel, and the gap between the ash portion and the solubility was stable with minimum fluctuations in the solubility trend (Fig. 10). In the case where pellet fuels were used, the silica in pellet fuels was crystalized and turned into a carcinogenic substance because pellet fuels were more influenced by temperature and incineration duration than stick fuels. Thus, the ash of those fuels will remain for long duration, maybe for at least a few hours, and will be exposed to high temperature (more than $900^{\circ} \mathrm{C}$ ) in stoves and heaters. According to the results, stick fuels are better than pellet fuels in terms of the safety to human health and the use of its ash as a fertilizer. Furthermore, on comparing the compact fuels with the existing form (as-are) of fuel, the presence or absence of washing strongly influenced the solubility. Rice husks should be washed for their use as a fuel in residential stoves and small commercial heaters. The two types of rice husk fuels used in this study were washed. The solubility would be highly deteriorated, unlike the solubility in Fig. 10, if the fuels were synthesized from as-are unwashed. Under washed conditions, the use of as-are (the existing form of rice husk) as a fuel was better than the compact fuels in terms of the ash use for fertilizer; however, the selection of rice husk as a fuel must be carefully determined because the existing form of rice husks have a high disadvantage during collection and hauling [1]. 


\section{Conclusions}

- The pellet fuel sample incinerated for 15 min was very stable in terms of solubility at all temperatures, which remained at nearly $50 \%$.

- The most stable stick fuel sample was the 30 min sample, with its solubility fluctuating between $40 \%$ and $50 \%$.

- The solubility of the pellet fuel after 60 min of incineration exceeded $80 \%$, reaching its highest value at $500^{\circ} \mathrm{C}$, while that of the stick fuel reached only $60 \%$, which was the highest value for the stick fuel.

- A decreasing trend in solubility was more significant for stick fuel samples than for pellet fuel samples because pellet fuel had a larger surface area than stick fuels.

- Regardless of the calcination duration, the as-are washed samples showed an increase in solubility at low temperatures and almost stable solubility trends up to $900^{\circ} \mathrm{C}$, while as-are unwashed samples showed a decrease in solubility as the calcination temperature increased.

- The trends between the two fuels differed; conversely, the solubility trends between the stick fuel and asare washed samples were very similar.

- Fixed carbon majorly left behind in the ash of compact rice husks was observed.

- Stick fuel was better than pellet fuel because the solubility trends of stick fuel as a function of calcination temperatures were more stable than those of pellet fuel.

- Stick fuels are better than pellet fuels in terms of safety and the use of ash as a fertilizer.

- Rice husks should be washed for use as fuel in residential stoves and small commercial heaters.

Stick fuels were the preferred type of rice husk ash for their use as fertilizer and for their use in residential stoves and small commercial heaters. However, the existing form of risk husks was better than the compact stick fuels under washed conditions. Therefore, selection of the type of rice husk fuel is based on the application of the fuels.

\section{Declarations}

\section{Availability of data and materials}

All data generated or analyzed during this study can be provided upon requests.

\section{Competing interests}

The authors declare they have no competing interests. 


\section{Funding}

This work was supported by Toyama Prefectural University Research Funds.

\section{Authors' contributions}

The present study was carried out in collaboration among the authors. RS designed, performed, analyzed, interpreted, and drafted manuscript. V.C.L, MT and HT provided technical support and revised the manuscript, and also supervised the research. All the authors read and approved the final manuscript.

\section{Acknowledgements}

The authors wish to thank colleagues who helped their reseach.

\section{Authors' information (optional)}

\section{References}

1. Sekifuji R, Le Van C, Tateda M, Takimoto H. Sustainability of a rice husk recycling scheme. International journal of recycling organic waste in agriculture. 2020,9(4).

2. Sheng C, Azevedo JL. Estimating the higher heating value of biomass fuels from basic analysis data. Biomass and bioenergy. 2005,28(5):499-507.

3. Yadav K, Tyagi M, Kumari S, Jagadevan S. Influence of process parameters on optimization of biochar fuel characteristics derived from rice husk: a promising alternative solid fuel. BioEnergy Research. 2019,12(4):1052-65.

4. Tateda M. Production and effectiveness of amorphous silica fertilizer from rice husks using a sustainable local energy system. Journal of Scientific Research and Reports. 2016:1-2.

5. Zinla D, Gbaha P, Koffı PM, Koua BK. Characterization of rice, coffee and cocoa crops residues as fuel of thermal power plant in Côte d'Ivoire. Fuel. 2021,283:119250.

6. Aslam U, Ramzan N, Aslam Z, Iqbal T, Sharif S, Hasan SW, Malik A. Enhancement of fuel characteristics of rice husk via torrefaction process. Waste Management \& Research. 2019,37(7):737-45.

7. Singh RI, Mohapatra SK, Gangacharyulu D. Studies in an atmospheric bubbling fluidized-bed combustor of $10 \mathrm{MW}$ power plant based on rice husk. Energy conversion and management. 2008 Nov 1,49(11):3086-103.

8. Yoon SJ, Son YI, Kim YK, Lee JG. Gasification and power generation characteristics of rice husk and rice husk pellet using a downdraft fixed-bed gasifier. Renewable Energy. 2012 Jun 1,42:163-7.

9. Unrean P, Fui BC, Rianawati E, Acda M. Comparative techno-economic assessment and environmental impacts of rice husk-to-fuel conversion technologies. Energy. 2018 May 15,151:58193. 
10. Lim JS, Manan ZA, Alwi SR, Hashim H. A review on utilisation of biomass from rice industry as a source of renewable energy. Renewable and sustainable energy reviews. 2012,16(5):3084-94.

11. Quispe I, Navia R, Kahhat R. Energy potential from rice husk through direct combustion and fast pyrolysis: a review. Waste management. 2017,59:200-10.

12. Sekifuji R, Tateda M. Taste evaluation of rice grown in soil treated with commercial silica and recycled rice husk silica. Journal of Scientific Research and Reports. 2017:1-9.

13. Sekifuji R, Tateda M. Study of the feasibility of a rice husk recycling scheme in Japan to produce silica fertilizer for rice plants. Sustainable Environment Research. 2019 Dec,29(1):1-9.

14. Pode R. Potential applications of rice husk ash waste from rice husk biomass power plant. Renewable and Sustainable Energy Reviews. 2016,53:1468-85.

15. Tateda M, Sekifuji R, Yasui M, Yamazaki A. A proposal for measuring solubility of the silica in rice husk ash. J Sci Res Rep. 2016,11(3):1-1.

16. Ríos-Badrán IM, Luzardo-Ocampo I, García-Trejo JF, Santos-Cruz J, Gutiérrez-Antonio C. Production and characterization of fuel pellets from rice husk and wheat straw. Renewable Energy. 2020,145:500-7.

17. Lenher V, Merrill HB. THE SOLUBILITY OF SILICA. Journal of the American Chemical Society. 1917,39(12):2630-8.

18. Holt PF, King DT. Solubility of silica. Nature. 1955 Mar,175(4455):514-5.

19. Lanning FC, Ponnaiya BW, Crumpton CF. The chemical nature of silica in plants. Plant Physiology. 1958,33(5):339.

20. Lanning FC. Plant constituents, silicon in rice. Journal of Agricultural and Food Chemistry. 1963,11(5):435-7.

21. FAMIC (Food and Agricultural Materials Inspection Center). Standard Method for Fertilizer Analysis (in Japanese). 2015. http://www.famic.go.jp/ffis/fert/obj/shikenho_2016_3.pdf\#page=1 Accessed 30 Jan 2021.

22. Sekifuji R, Le VC, Tateda M, Takimoto H. Solubility and physical composition of rice husk ash silica as a function of calcination temperature and duration. International journal of recycling organic waste in agriculture. 2021 Mar 1,10(1):19-27.

23. JIS (Japan Industrial Standard). Coal and coke - Methods for proximate analysis, (in Japanese). https://kikakurui.com/m/M8812-2006-01.html Accessed 29 March 2020.

24. NAKATA Y, SUZUKI M, OKUTANI T, KIKUCHI M, AKIYAMA T. Preparation and properties of SiO2 from rice hulls. Journal of the Ceramic Society of Japan. 1989 Aug 1,97(1128):842-9.

25. Real C, Alcala MD, Criado JM. Preparation of silica from rice husks. Journal of the American ceramic society. 1996,79(8):2012-6.

26. Shinohara Y, Kohyama N. Quantitative analysis of tridymite and cristobalite crystallized in rice husk ash by heating. Industrial health. 2004,42(2):277-85. 
27. Tateda M, Sekifuji R, Yasui M, Yamazaki A. Case study: Technical consideration to optimize rice husk burning in a boiler to retain a high solubility of the silica in rice husk ash. Sci. Res. Reports. 2016,11(4):1-11.

\section{Figures}

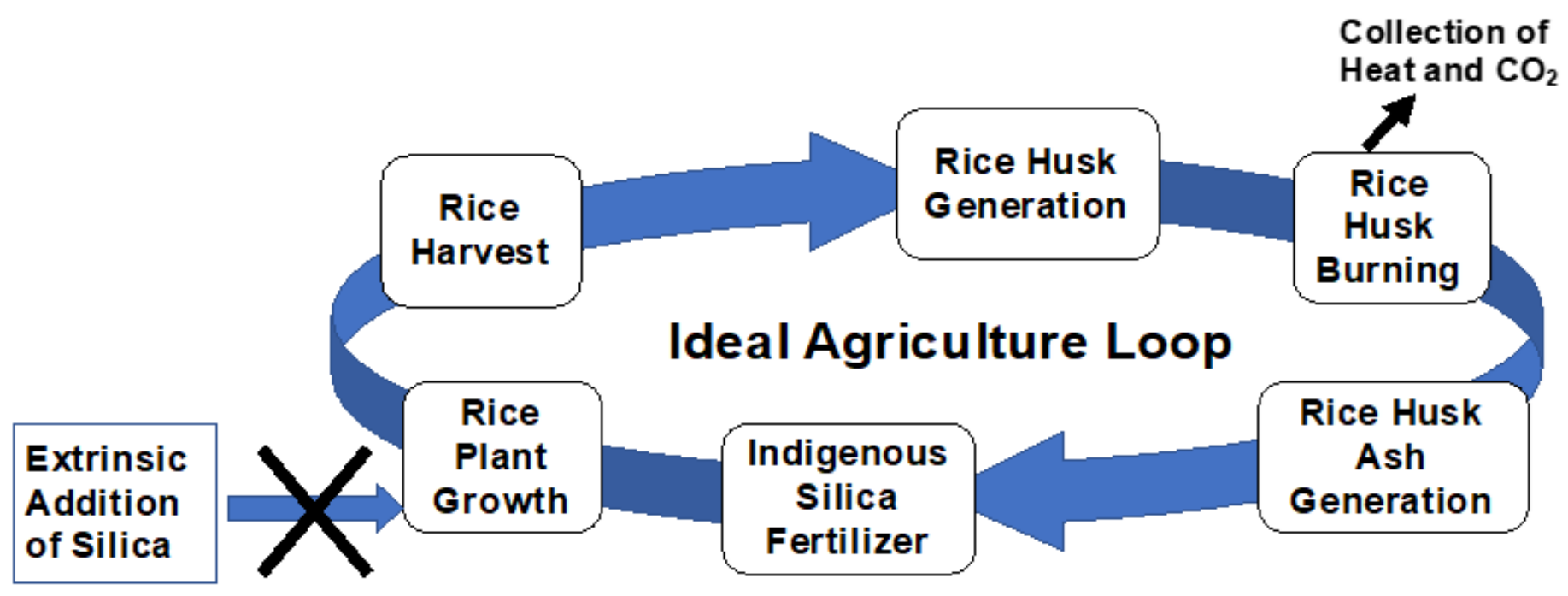

Figure 1

Ideal agriculture loop
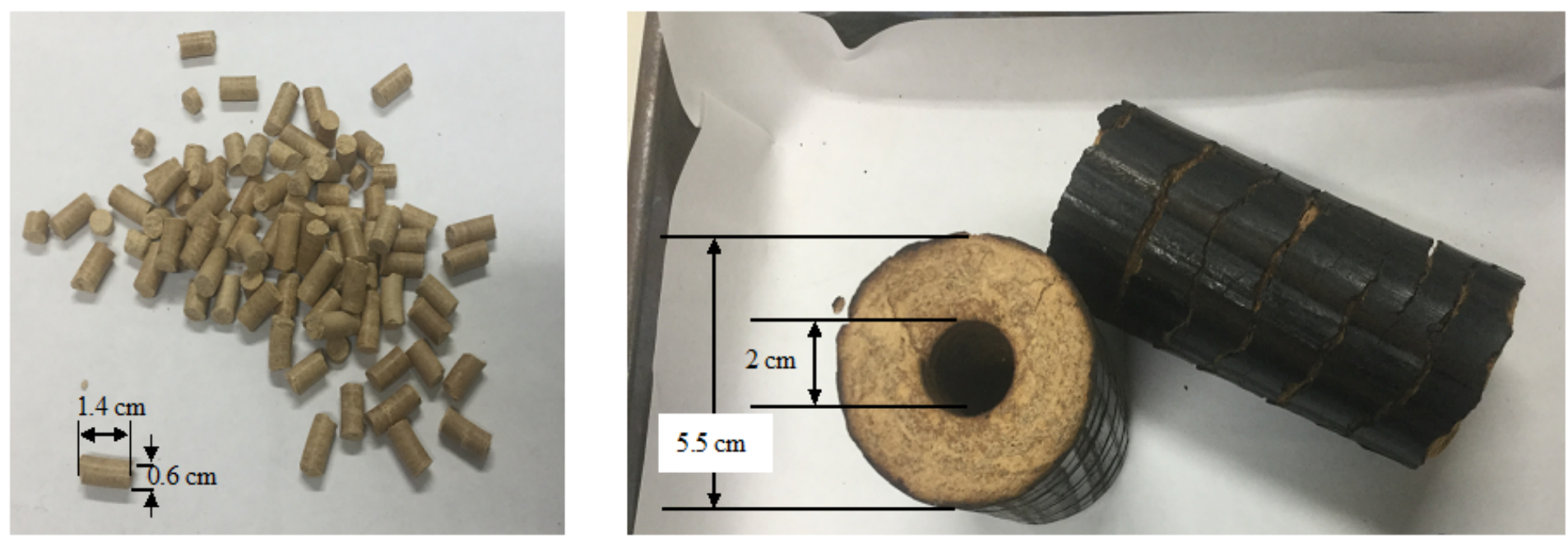

Figure 2

Compressed rice husk fuels: Pellet fuel (left), Stick fuel (right) 


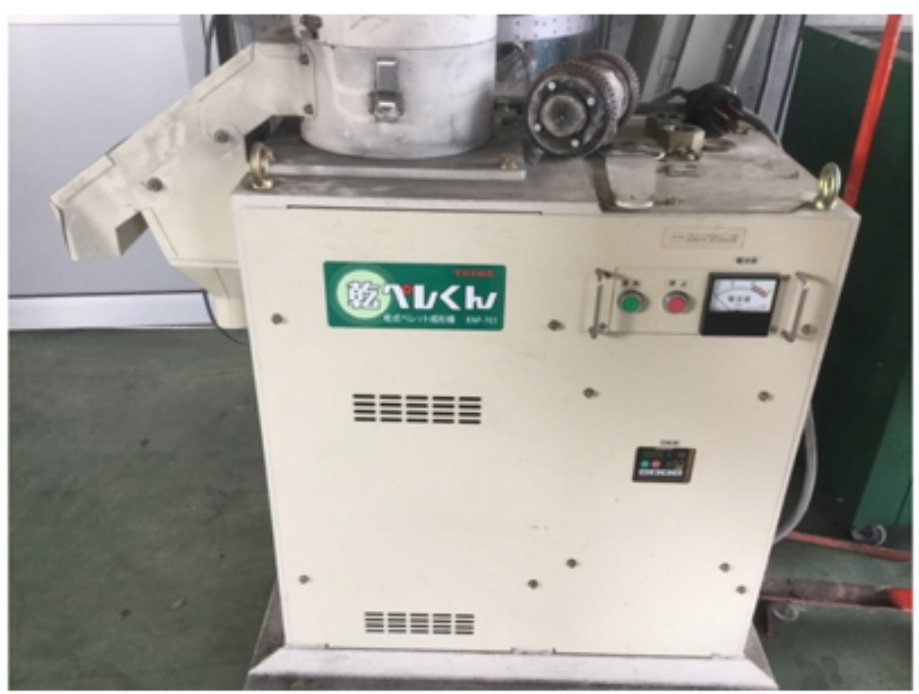

KNP-701

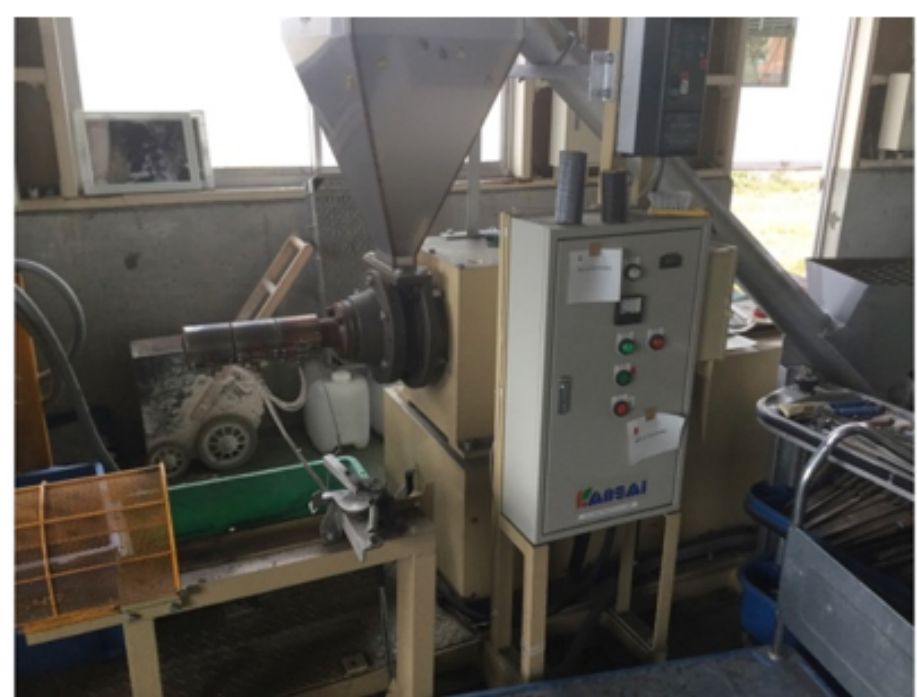

FHM-120

\section{Figure 3}

Pelletization and Solidification Machines

(A)

(B)

(C)
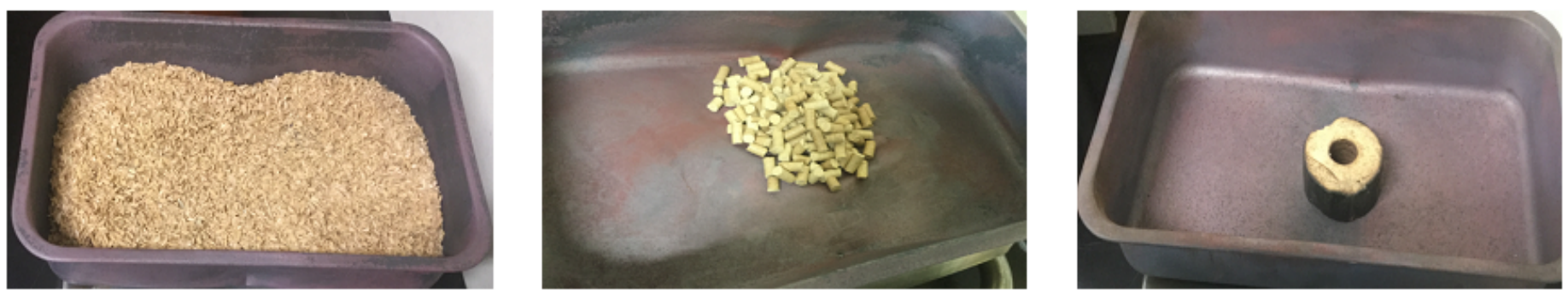

Figure 4

Incinerating conditions in vats: As-are washed (A), pellet fuel (B), and stick fuel (C) 


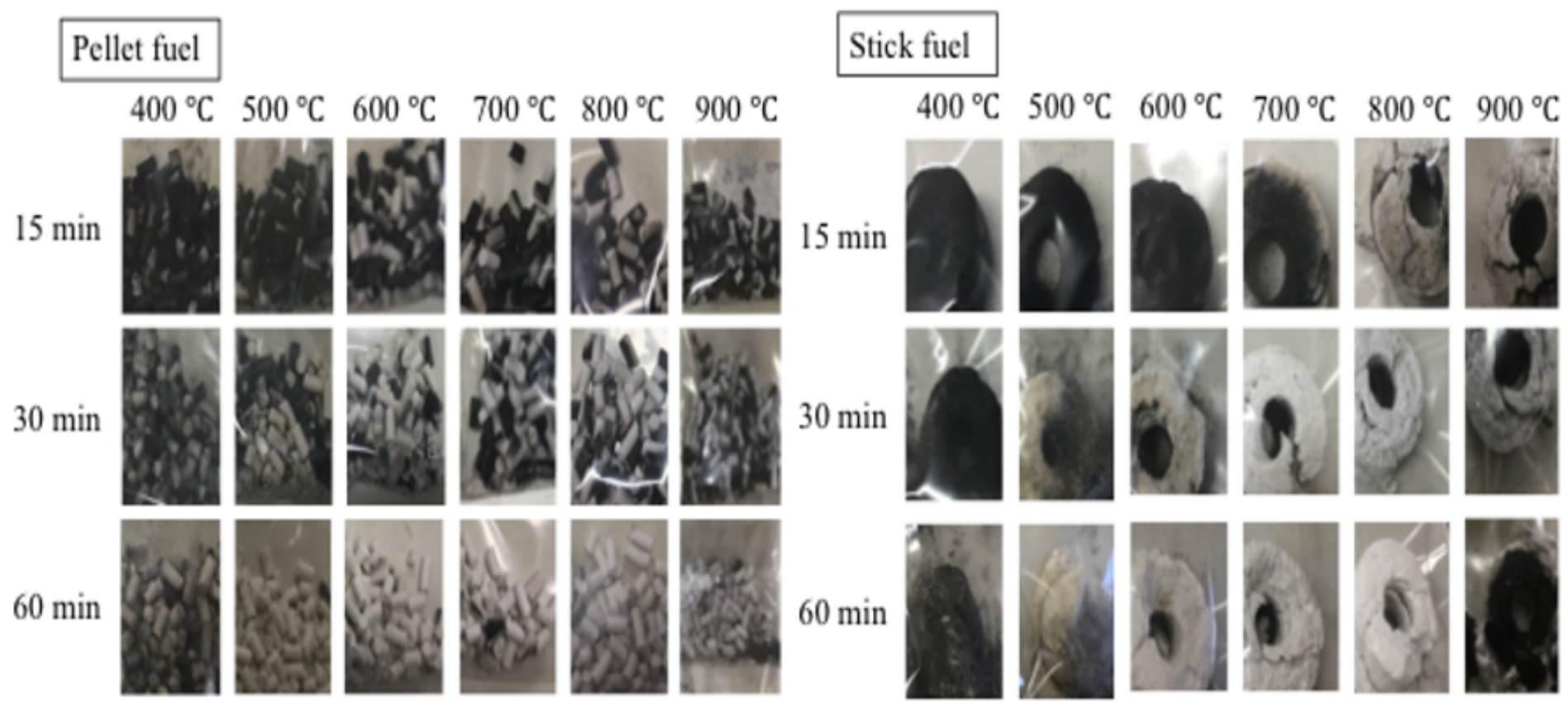

Figure 5

Incinerated pellet (left) and stick (right) fuels.

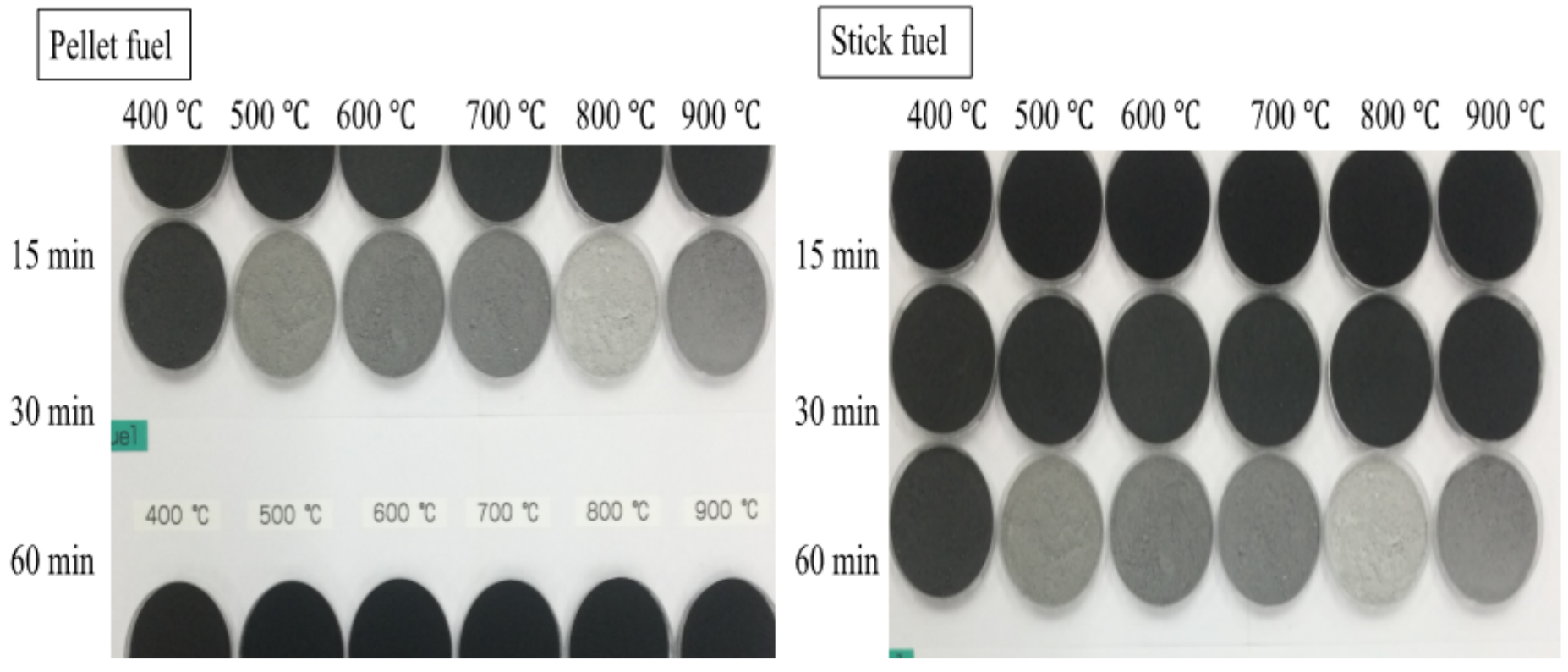

Figure 6

Powdered pellet (left) and stick (right) fuels 


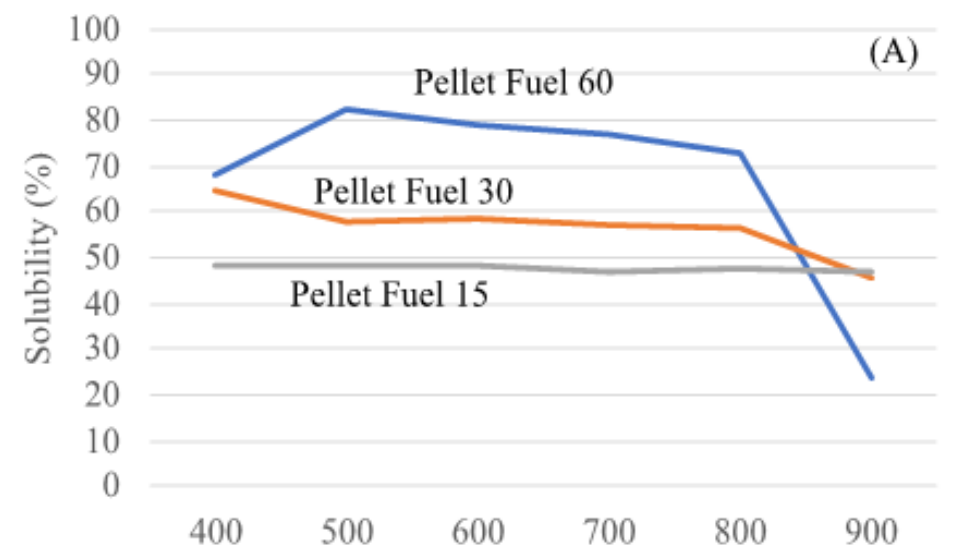

Calcination Temperature $\left({ }^{\circ} \mathrm{C}\right)$

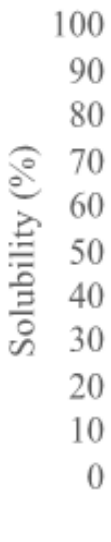

400

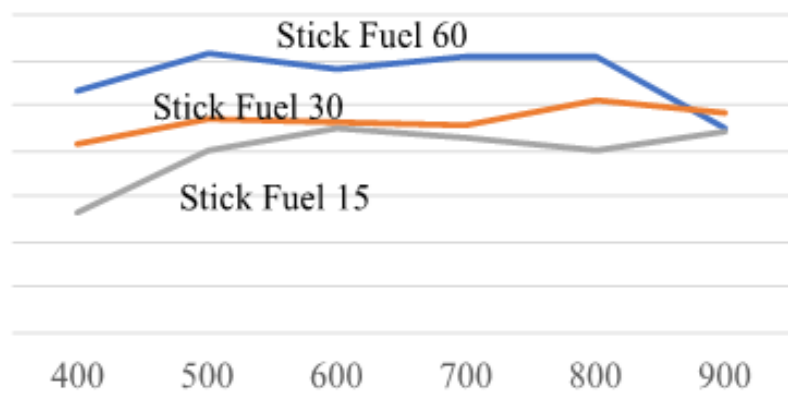

Calcination Temperature $\left({ }^{\circ} \mathrm{C}\right)$

\section{Figure 7}

Solubility trends as a function of incineration temperatures for (A) pellet and (B) stick fuels.

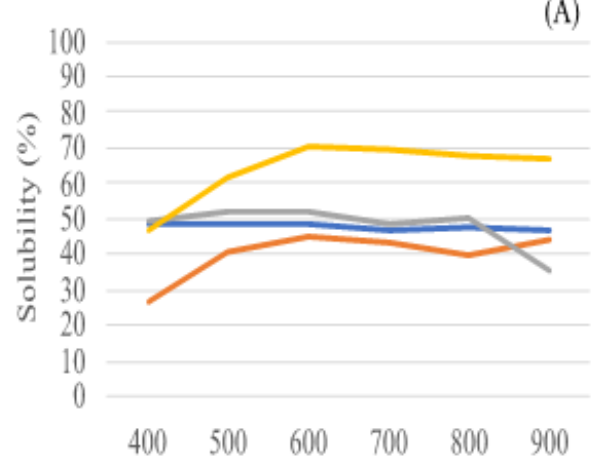

Calcination Temperature $\left({ }^{\circ} \mathrm{C}\right)$

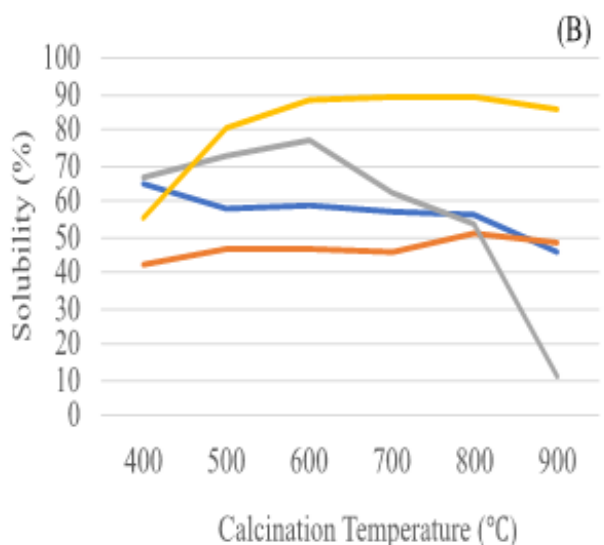

(B)

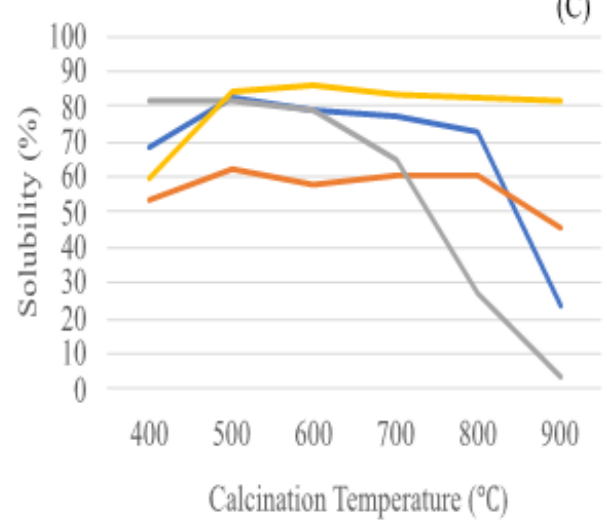
As-are washed
Stick Fuel

As-are unwashed

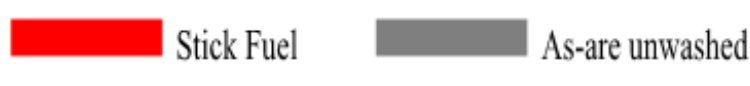

\section{Figure 8}

Solubility comparison under (A) $15 \mathrm{~min},(B) 30 \mathrm{~min}$, and (C) $60 \mathrm{~min}$ incineration duration between pellet and stick fuels as a function of burning temperatures including as-are samples 
As-are unwashed

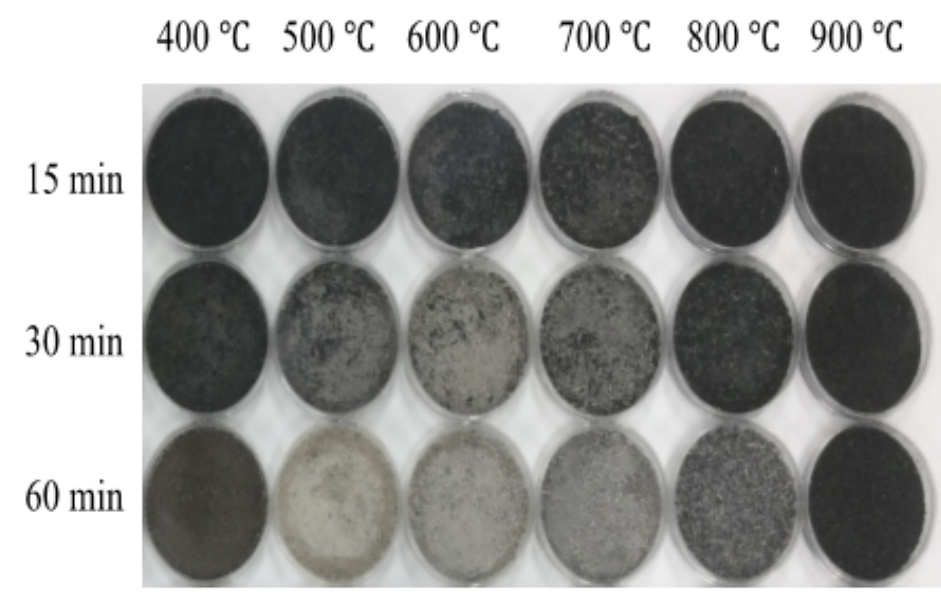

As-are washed

$400{ }^{\circ} \mathrm{C} \quad 500^{\circ} \mathrm{C} \quad 600^{\circ} \mathrm{C} \quad 700^{\circ} \mathrm{C} \quad 800^{\circ} \mathrm{C} \quad 900^{\circ} \mathrm{C}$

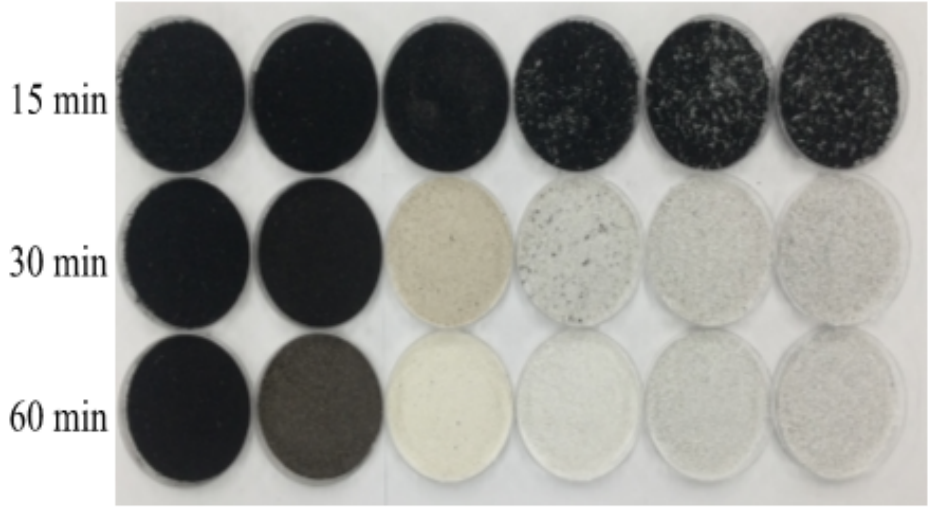

Figure 9

Appearance of as-are unwashed (left) and washed (right) samples 

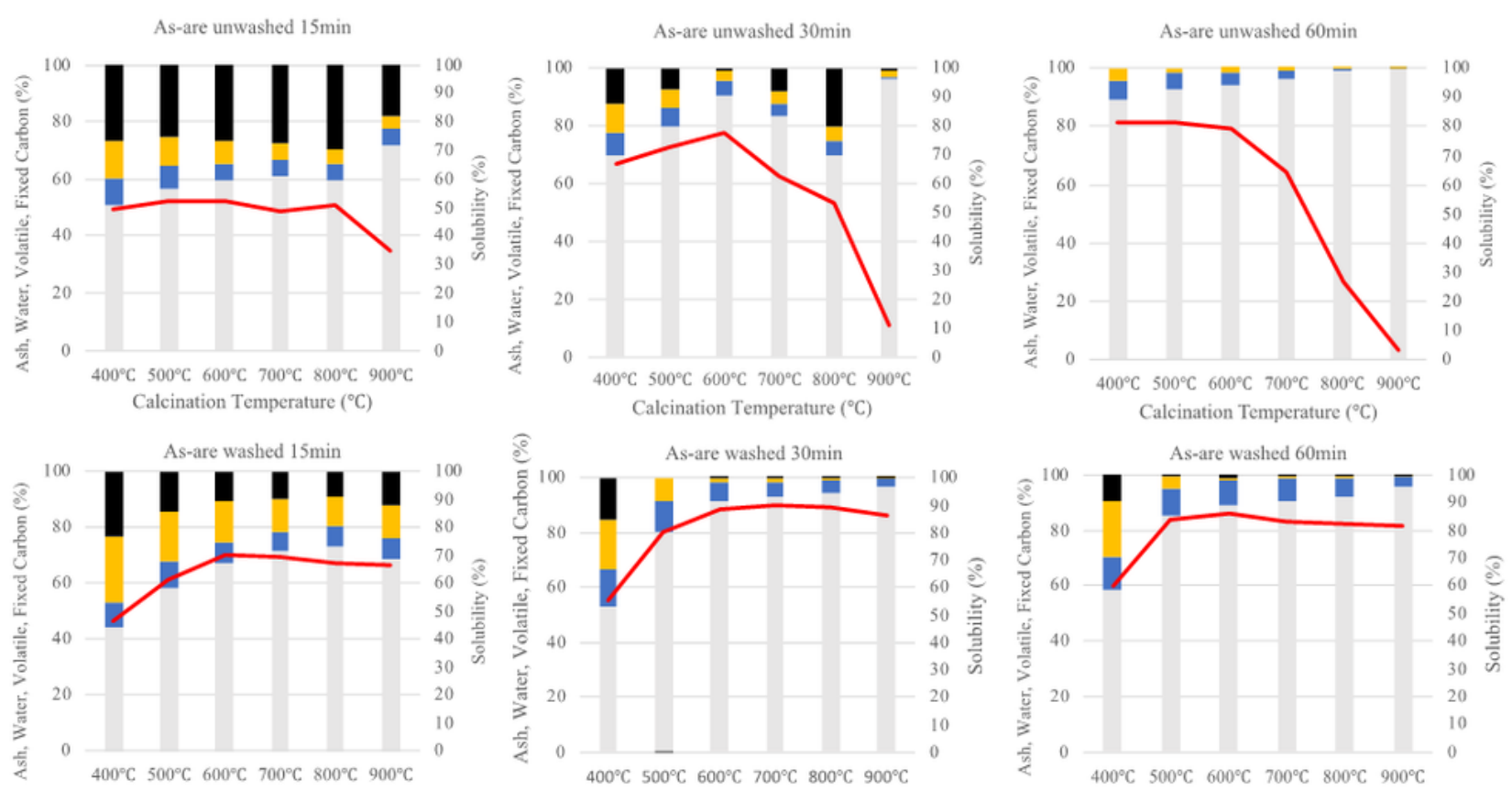

Calcination Temperature $\left({ }^{\circ} \mathrm{C}\right)$

Calcination Temperature $\left({ }^{\circ} \mathrm{C}\right)$

Calcination Temperature $\left({ }^{\circ} \mathrm{C}\right)$
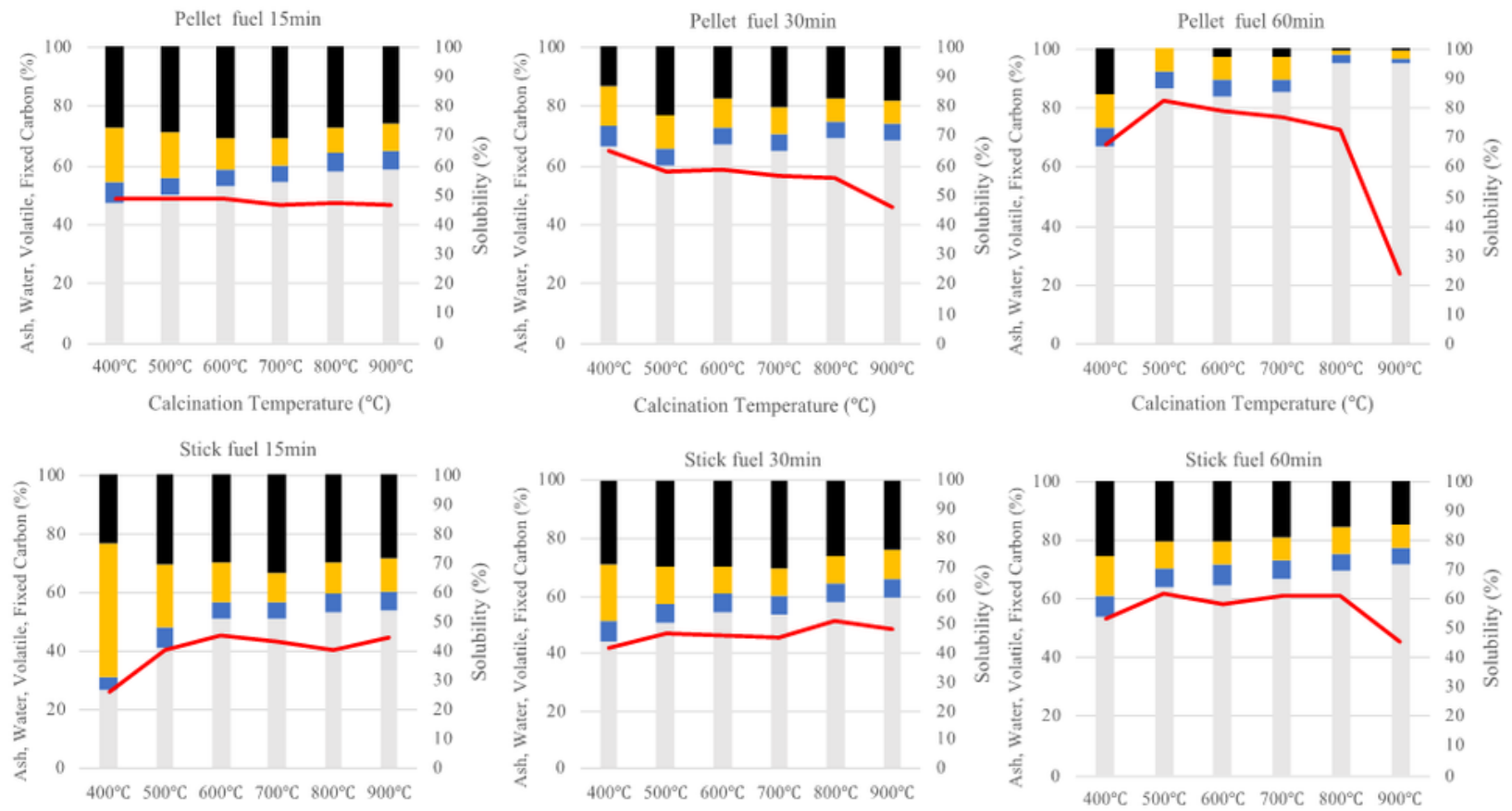

Calcination Temperature $\left({ }^{\circ} \mathrm{C}\right)$

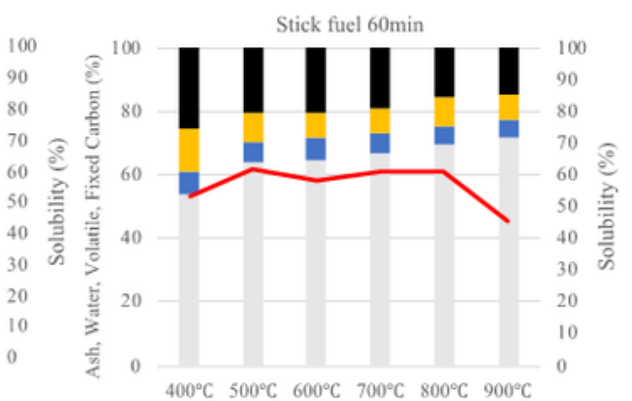

Calcination Temperature $\left({ }^{\circ} \mathrm{C}\right)$

Figure 10

Physical properties and solubility for the four samples 


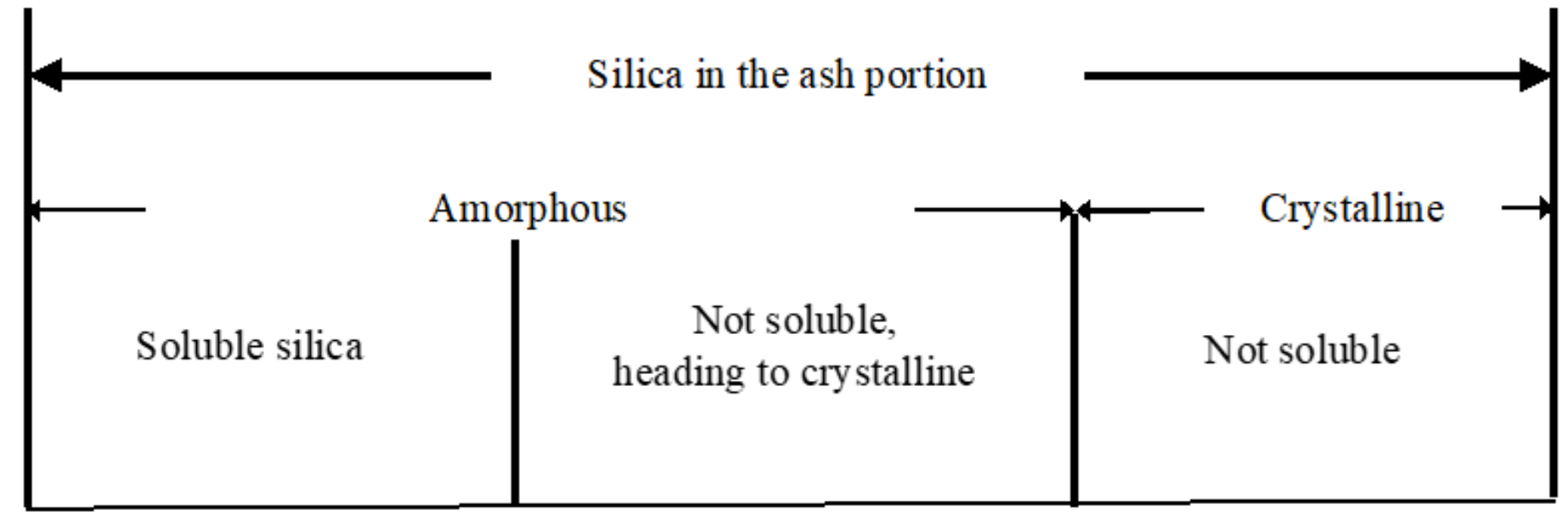

Figure 11

Physical state of silica in the ash portion in the calcinated rice husk ash. 